\title{
Impaired Motor Learning in the Vestibulo-Ocular Reflex in Mice with Multiple Climbing Fiber Input to Cerebellar Purkinje Cells
}

\author{
Rhea R. Kimpo and Jennifer L. Raymond \\ Department of Neurobiology, Stanford University, Stanford, California 94305-5125
}

\begin{abstract}
A unique feature of the cerebellar architecture is that Purkinje cells in the cerebellar cortex each receive input from a single climbing fiber. In mice deficient in the $\gamma$ isoform of protein kinase $\mathrm{C}\left(P K C \gamma^{-/-}\right.$mice $)$, this normal architecture is disrupted so that individual Purkinje cells receive input from multiple climbing fibers. These mice have no other known abnormalities in the cerebellar circuit. Here, we show that $P K C \gamma^{-1-}$ mice are profoundly impaired in vestibulo-ocular reflex (VOR) motor learning. The $P K C \gamma^{-1-}$ mice exhibited no adaptive increases or decreases in VOR gain at training frequencies of $2 \mathrm{or} 0.5 \mathrm{~Hz}$. This impairment was present across a broad range of peak retinal slip speeds during training. We compare the results for VOR motor learning with previous studies of the performance of $P K C \gamma^{-1-}$ mice on other cerebellum-dependent learning tasks. Together, the results suggest that single climbing fiber innervation of Purkinje cells is critical for some, but not all, forms of cerebellum-dependent learning, and this may depend on the region of the cerebellum involved, the organization of the relevant neural circuits downstream of the cerebellar cortex, as well as the timing requirements of the learning task.
\end{abstract}

Key words: climbing fiber; motor learning; cerebellum; vestibulo-ocular reflex; oculomotor; mouse

\section{Introduction}

The climbing fiber input to the cerebellum from the inferior olive is thought to play a key role in cerebellum-dependent learning (Marr, 1969; Albus, 1971; Ito, 1972). Climbing fiber activity during the induction of learning correlates with changes in behavior, and electrical stimulation of climbing fibers can trigger longlasting changes in the strength of simultaneously active synapses in the cerebellar cortex (Gilbert and Thach, 1977; Ito et al., 1982a; Watanabe, 1984; Mauk et al., 1986; Sears and Steinmetz, 1991; Hartell, 1996; Hesslow and Ivarsson, 1996; Eilers et al., 1997; Katoh et al., 1998; Kim et al., 1998; Raymond and Lisberger, 1998; Jorntell and Ekerot, 2002). A unique feature of the climbing fiber input to the cerebellum is that each Purkinje cell in the cerebellar cortex generally receives input from only a single climbing fiber (Eccles et al., 1967; Kano et al., 1995; Hashimoto and Kano, 2003; Nishiyama and Linden, 2004). To evaluate the functional relevance of this unique architecture, we studied a strain of mice in which Purkinje cells receive multiple climbing fiber inputs. In particular, we studied motor learning in mice deficient in the $\gamma$ isoform of protein kinase $\mathrm{C}\left(\mathrm{PKC} \gamma^{-1-}\right.$ mice) (Abeliovich et al., 1993a).

PKC has three "classical," $\mathrm{Ca}^{2+}$-dependent isoforms that have been implicated in many aspects of neuronal function. The $\alpha$ and

Received Dec. 7, 2006; revised April 12, 2007; accepted April 16, 2007.

This work was supported by National Science Foundation Grant DBI-0208400 (R.R.K.) and National Institutes of Health Grant R01 DC004154 and an EJLB Foundation Award (J.L.R.). We thank members of the Raymond laboratory, especially Pamela W. Louderback, Robin S. Booth, and Katherine $0 \mathrm{~h}$ for technical assistance.

Correspondence should be addressed to Dr. Jennifer L. Raymond, Department of Neurobiology, Stanford University, 299 Campus Drive West, Stanford, CA 94305-5125. E-mail: jenr@stanford.edu.

DOI:10.1523/JNEUROSCI.0801-07.2007

Copyright $\odot 2007$ Society for Neuroscience $\quad$ 0270-6474/07/275672-11\$15.00/0 $\beta$ isoforms are broadly expressed in the brain throughout life and play important roles in such fundamental functions as neurotransmitter release, synaptic plasticity, neurite development, and the regulation of neurotransmitter receptor clustering and internalization (Cambray-Deakin et al., 1990; Ben-Shlomo et al., 1991; Coffey et al., 1993; Brandon et al., 1999; Fan et al., 2002; Gundlfinger et al., 2003; Leitges et al., 2004; Tatsukawa et al., 2006) (for review, see Tanaka and Saito, 1992; Silinsky and Searl, 2003). In contrast, the $\gamma$ isoform of PKC is expressed in only a few specific types of neurons in the brain, such as the Purkinje cells in the cerebellum, pyramidal and granule cells in the hippocampus, and lamina II neurons in the dorsal horn of the spinal cord (Saito et al., 1988; Tanaka and Saito, 1992; Van Der Zee et al., 1997). Even in such cells, PKC $\gamma$ does not appear to be essential for synaptic transmission or plasticity but rather seems to play more selective roles. For example, in the hippocampus of $P K C \gamma^{-/-}$ mice, the effective stimulus for inducing long-term potentiation (LTP) is altered, and, in the spinal cord, the development of long-term hyperexcitability of pain transmission neurons is disrupted (Abeliovich et al., 1993a; Martin et al., 2001) (for review, see Saito and Shirai, 2002).

In the cerebellum, PKC $\gamma$ plays a role in normal development of the climbing fiber input from the inferior olive (Hashimoto et al., 1988; Moriya and Tanaka, 1994; Kano et al., 1995). Expression of PKC $\gamma$ in the brain peaks during the critical period for synapse formation (Hashimoto et al., 1988; Huang et al., 1990; Moriya and Tanaka, 1994). The deletion of PKC $\gamma$ causes a developmental defect in the elimination of supernumerary climbing fiber-Purkinje cell synapses so that multiple climbing fiber innervation of Purkinje cells persists into adulthood (Kano et al., 1995). This multiple climbing fiber innervation can be detected 
in vitro as the presence of more than one discrete EPSC response in a Purkinje cell when the white matter is stimulated at various intensities to activate the climbing fibers (Kano et al., 1995; Hashimoto and Kano, 2003; Nishiyama and Linden, 2004). No other abnormalities have been observed in the cerebellum of the $P K C \gamma^{-/-}$mice, despite extensive analysis. Within the cerebellar cortex and its targets, PKC $\gamma$ is expressed only in Purkinje cells (Bareggi et al., 1996; Garcia and Harlan, 1997; Barmack et al., 2000; Shutoh et al., 2003). The morphology, synaptic density, EPSCs, $\mathrm{Ca}^{2+}$ currents and short-term plasticity of Purkinje cells are normal, as well as the regional projections of climbing fibers to the vestibulocerebellum, targets of the vestibulocerebellum, and eye movements evoked by vestibulocerebellar stimulation (Chen et al., 1995; Kano et al., 1995; Shutoh et al., 2003). Notably, long-term depression (LTD) of the parallel fiber-Purkinje cell synapses, a form of synaptic plasticity implicated in cerebellumdependent learning, depends on the $\alpha$ isoform of PKC and can be induced to normal levels in vitro in $\mathrm{PKC} \gamma^{-1-}$ mice (Chen et al., 1995; Leitges et al., 2004). Thus, by all measures, the effect of PKC $\gamma$ deletion on the cerebellar circuit appears to be specific for the development of the climbing fiber-Purkinje cell synapses.

At the behavioral level, broad-spectrum PKC inhibitors in the cerebellum as a whole (Shutoh et al., 2003) or specifically in Purkinje cells (De Zeeuw et al., 1998b; Koekkoek et al., 2003) have been reported to abolish cerebellum-dependent learning. In contrast, $P K C \gamma^{-1-}$ mice have a more subtle behavioral phenotype, with sparing of some cerebellum-dependent behaviors. Although $P K C \gamma^{-1-}$ mice have impaired motor coordination on rotorod tests, eyeblink conditioning is enhanced in these mice. This led to the hypothesis that single climbing fiber innervation of Purkinje cells is critical for complex, coordinated movements but not for the modification of simple, elemental movements by the cerebellum (Chen et al., 1995). However, a more recent study reported that adaptation of the optokinetic reflex (OKR), another simple, cerebellum-dependent motor learning task, is partially impaired in $P K C \gamma^{-/-}$mice (Shutoh et al., 2003). Thus, the differential effects of $P K C \gamma^{-/-}$deletion cannot be fully explained by the complexity of the motor task.

One possibility is that $P K C \gamma^{-/-}$deletion and multiple climbing fiber innervation have a variable effect on the function of different cerebellar regions. A recent study reported that Purkinje cells in cerebellar sulci exhibit some degree of multiple climbing fiber innervation, even in adult, wild-type mice, suggesting that some cerebellar regions may function well with multiple climbing fiber innervation (Nishiyama and Linden, 2004). Eyeblink conditioning, the OKR, and rotorod performance all depend on different regions of the cerebellum (Le Marec and Lalonde, 1997; Katoh et al., 1998; Gerwig et al., 2005; Villarreal and Steinmetz, 2005). Thus, a region-dependent effect of multiple climbing fiber innervation could differentially affect these tasks.

Here, we examine motor learning in the vestibulo-ocular reflex (VOR) in the $P K C \gamma^{-/-}$mice, because this task depends on the flocculus, the same region of the cerebellum that mediates OKR adaptation (Ito et al., 1982b; Nagao, 1983; Lisberger et al., 1984; Luebke and Robinson, 1994; Katoh et al., 1998; McElligott et al., 1998; Rambold et al., 2002). The VOR and OKR also share circuitry downstream of the cerebellum, including the vestibular and oculomotor nuclei (De Zeeuw et al., 1998a). The VOR and OKR circuitry upstream of the cerebellum are different, but neither of the upstream pathways express PKC $\gamma$ (Garcia and Harlan, 1997; Barmack et al., 2000). We examined whether PKC $\gamma$ deletion and the resultant multiple climbing fiber innervation had the same effects on motor learning in the VOR as it does on motor learning in the OKR.

\section{Materials and Methods}

Subjects. Experiments were performed on male adult ( $\geq 8$ weeks) mice deficient in the $\gamma$ isoform of PKC $(n=42)$ and wild-type animals $(n=$ 40) with the genetic background from which the $P K C \gamma^{-1-}$ mice were derived (B6129PF2/J; The Jackson Laboratory, Bar Harbor, ME) (Abeliovich et al., 1993b). All mice used for the experiments had dark eyes. Some of the wild-type mice used for the experiments described in this paper were also used in another study (Kimpo et al., 2005). All animal protocols were approved by the Stanford University Administrative Panel for Laboratory Animal Care.

Surgical preparation. Mice were prepared for behavioral experiments as described previously (Boyden and Raymond, 2003; Kimpo et al., 2005). In summary, while the mouse was under ketamine-isoflurane anesthesia, a head post was attached to the top of the skull using anchor screws and dental acrylic, and a scleral search coil (IET, Marly, Switzerland) weighing $\sim 50 \mathrm{mg}$ was implanted on the temporal side of the right eye, beneath the conjunctiva. The search coil leads were run subcutaneously to a two-pin connector. Mice were allowed to recover from surgery for 5-7 d before behavioral testing, and those with eye scarring after surgery were excluded from the study (five $P K C \gamma^{-1-}$ and one wt).

Experiments. The head of the mouse was immobilized by attaching the implanted head post to a restrainer. The restrainer was placed on a turntable (Carco IGTS, Pittsburgh, PA) that delivered a vestibular stimulus by rotating the mouse about the vertical axis. The restrained mouse was positioned in the center of a magnetic field generated by a set of 18-inch magnetic coils (CNC Engineering, Seattle, WA) that was fixed to the turntable. The magnetic coils generated signals in the scleral search coil related to the eye position. An analog differentiator and filter with a 300 $\mathrm{Hz}$ corner frequency were used to obtain eye velocity from eye position. The eye coil method (Robinson, 1963; Judge et al., 1980; Koekkoek et al., 1997) was chosen because it provides a stable and precise measurement of mouse eye movements and is therefore particularly reliable for measuring learned changes in the VOR (Stahl et al., 2000; Boyden and Raymond, 2003).

Visual image motion was delivered by an optokinetic drum, a translucent half-dome with black and white vertical stripes, each of which subtended $7.5^{\circ}$ of visual angle. The optokinetic drum was backlit by two 60 $\mathrm{W}$ lamps. A silvered acrylic plate attached to the turntable helped to ensure that the motion of the drum filled most of the mouse's field of view (approximately two-thirds of the sphere subtended by the optokinetic dome and its reflection).

Mice were first acclimatized to the head restrainer, during which the eye coils were calibrated by moving the magnetic coils relative to the stationary mouse using sinusoidal velocity profiles, each with a frequency of 0.5 or $2 \mathrm{~Hz}$ with $\pm 10^{\circ}$ s peak velocity. This calibration was performed with the mouse in total darkness.

Motor learning in the VOR was induced by pairing rotation of the mouse (vestibular stimulus) with rotation of the visual stimulus. For all training conditions, the vestibular stimulus had a sinusoidal velocity profile with $\pm 10 \%$ s peak velocity and a frequency of 0.5 or $2 \mathrm{~Hz}$. The visual stimulus moved at the same frequency as the head, with a peak velocity relative to the head of $0,2.5,5,7.5,12.5,15$, or $20^{\circ}$ s, to create training conditions with ideal VOR gains (to stabilize the visual image) of $0,0.25,0.5,1.5,1.75$, or 2 , respectively, which we refer to as $\times 0$ (or gain-down), $\times 0.25, \times 0.5, \times 1.25, \times 1.5, \times 1.75$, and $\times 2$ (or gain-up), respectively. Before and after training, the VOR was measured in the dark by collecting $5-1018$-s data files, with a bright light flashed briefly between collections to keep the animal alert, followed by an $8-10$ s pause before the next collection. The OKR was also measured at the training frequency before training.

Individual mice were run on more than one training condition. To allow the VOR gain to return to baseline, mice were placed in their home cages in a normal visual-vestibular environment between experiments for at least $48 \mathrm{~h}$ after an increase in VOR gain and at least $72 \mathrm{~h}$ after a decrease in VOR gain. These time periods were sufficient to allow the VOR gain to return to baseline (Kimpo et al., 2005). In general, training 
conditions that increased or decreased the VOR gain were alternated for each mouse.

Data analysis. All signals were digitized at a sampling frequency of 500 $\mathrm{Hz}$. In wild-type mice, $\sim 6 \%$ of the $2 \mathrm{~Hz}$ stimulus cycles contained saccades, and $\sim 21 \%$ of the $0.5 \mathrm{~Hz}$ stimulus cycles contained saccades. In $P K C \gamma^{-1-}$ mice, $\sim 11$ and $22 \%$ of the 2 and $0.5 \mathrm{~Hz}$ cycles, respectively, contained saccades. When possible, saccades were interpolated by a straight line. Stimulus cycles with saccades that subtended too much of the cycle to be interpolated or with other movement artifacts were deleted. The remaining eye velocity cycles were aligned on head velocity or optokinetic drum position and averaged. Using Fourier analysis, the amplitude and phase of the fundamental frequency of both eye and head velocity were measured. The gain of the VOR was defined as the ratio of the amplitudes of eye and head velocity. The phase of the VOR was calculated as the difference between the eye velocity phase and head velocity phase, minus $180^{\circ}$. A compensatory VOR would thus have a phase of $0^{\circ}$. Positive VOR phase values indicate phase lag of the eye velocity relative to the head velocity, and negative values indicate phase lead.

Data from experiments with unreliable VOR measurements were excluded from analysis. Two criteria were used to exclude experiments. One was if too few sinusoidal cycles of eye velocity remained for averaging after the exclusion of cycles with motion artifacts. We required at least 10 total cycles of eye velocity for the Fourier analysis measurements of the VOR before training and at least 10 cycles after training. The second criterion for exclusion was if measurements of the VOR before training, after training, or both were exceptionally variable. We required that the SD of the VOR gain across the $5-10$ data files was $<50 \%$ of the average VOR gain across these files. For $P K C \gamma^{-1-}$ mice and wild-type experiments, 1 of 275 and 2 of 132 experiments, respectively, were excluded because of too few cycles, and 27 of 275 and 12 of 132 experiments, respectively, were excluded because of highly variable VOR gain measurements. The variability in VOR gain measurements did not reflect any consistent trend for the VOR gain to increase or decrease with repeated testing; in $P K C \gamma^{-1-}$ mice, the baseline gain was higher in the last data file than in the first data file in $46 \%$ of the rejected experiments, and, in the other $54 \%$, the gain was lower. For the analysis of VOR phase changes, we also excluded experiments in which the $\mathrm{SD}$ was $>100^{\circ}$ before training, after training, or both (17 of 275 in $P K C \gamma^{-1-}$ and 4 of 132 in wt mice).

Retinal slip is defined as the velocity of the visual stimulus relative to the eye. The peak speed and phase of retinal slip were calculated from the amplitude and phase of the averaged eye and visual stimulus velocities during the first minute of visual-vestibular training.

Statistical analysis. Each mouse was subjected to one to three experiments using a given training condition. Data used for analysis were weighed equally across mice by averaging all data from the same training condition for each mouse before comparing between genotypes. Onesample $t$ tests were used to determine whether the change in VOR gain or phase for each training condition was significantly different from zero. Our conclusions on the learned changes in VOR for the full population of $P K C \gamma^{-1-}$ and wild-type mice were not affected by the application of a Bonferroni-corrected threshold $p$ value. Changes in VOR gain or phase could result from associative learning, which depends on the relative directions of head and visual stimulus movements during training or from nonassociative processes, such as habituation, which would occur equally during gain-up and gain-down training. To test for associative learning, changes in VOR gain and phase after gain-up training were compared with changes after gain-down training for a given training frequency and genotype by paired $t$ test. To determine differences in learning between $P K C \gamma^{-/-}$and wild-type mice, unpaired $t$ tests were performed for each training condition. Our conclusions regarding comparisons between the two genotypes were unaffected by the Bonferroni correction for the whole and matched populations (for description of how matched subpopulations were identified, see next paragraph). To test for any significant differences between $P K C \gamma^{-1-}$ and wild-type mice in baseline VOR and OKR gain and phase across different frequencies, we performed two-factor ANOVA tests for genotype and frequency. When genotype had a significant effect on the baseline performance, we performed Bonferroni-corrected unpaired $t$ tests between $P K C \gamma^{-1-}$ and wild-type at each frequency. We performed correlation analyses with Bonferroni correction for multiple tests to test for any significant relationship between baseline performance parameters and changes in VOR gain. Unless noted otherwise, the criterion significance level was $p<$ 0.05 .

To identify subpopulations of $P K C \gamma^{-1-}$ and wild-type mice with similar baseline VOR gains, we first ranked mice tested on a given training condition according to VOR gain. Then, for each training condition, wild-type mice with high and $P K C \gamma^{-1-}$ mice with low baseline VOR gains were excluded until the range was similar, and the average value was not significantly different between wild-type and $P K C \gamma^{-1-}$ mice, as determined by unpaired $t$ test $(p>0.05)$. Similar procedures were used to identify subpopulations of $P K C \gamma^{-1-}$ and wild-type mice with similar baseline OKR gains or matched retinal slip speed for each training condition. Note that for these analyses, the baseline gains and retinal slip were measured on the day of the experiment, whereas the VOR and OKR data for each mouse shown in Figure 2 were averaged across several days, for all training conditions.

A previous study (Shutoh et al., 2003) observed higher baseline VOR and OKR gains in $P K C \gamma^{-1-}$ mice than those measured in this study. However, the vestibular stimuli used in that previous study had higher peak velocities, which elicit higher VOR gains, and the optokinetic stimuli had lower velocities and frequencies, which elicit higher OKR gains (Iwashita et al., 2001; Van Alphen et al., 2001).

\section{Results}

\section{Impaired motor learning in the VOR in $P K C \gamma^{-/-}$mice}

The VOR helps to stabilize visual images on the retina by moving the eyes in the opposite direction of head movement. The gain of the VOR is defined as the ratio of eye speed to head speed during head movements in total darkness. The gain of the VOR can be modified by a cerebellum-dependent form of motor learning. Motor learning in the VOR was induced by presenting $P K C \gamma^{-1-}$ and wild-type mice with visual and vestibular stimuli paired in a way to increase (gain-up) or decrease (gain-down) the gain of the VOR. Wild-type mice exhibited adaptive changes in VOR gain, whereas the $P \mathrm{KC}^{-/-}$mice did not.

In all experiments, the head movements used to measure the VOR and to induce learning had sinusoidal velocity profiles with peak velocity of $\pm 10 \%$ s. During gain-up training, the visual stimulus moved at the same speed as the head but in the opposite direction, so that the ideal VOR gain was 2 (this training condition is often referred to as $\times 2$ ). In wild-type mice, 30 min of gain-up training using a visual-vestibular stimulus frequency of 2 $\mathrm{Hz}$ induced a significant, adaptive increase in the gain of the VOR (Fig. 1 $a$, white bars) ( $p<0.0001$, one sample $t$ test). During gain-down training, the visual stimulus moved exactly with the head, so that the ideal VOR gain was zero (this training condition is often referred to as $\times 0$ ). In wild-type mice, $30 \mathrm{~min}$ of gaindown training at $2 \mathrm{~Hz}$ induced a significant, adaptive decrease in the gain of the VOR (Fig. $1 a$, white bars) $(p<0.0001)$. In contrast, $P K C \gamma^{-1-}$ mice did not show any significant changes in VOR gain after gain-up or gain-down training (Fig. 1a, gray bars) $(p>0.15)$, and the changes were significantly different between wild-type and $P K C \gamma^{-1-}$ mice for both gain-up and gain-down training ( $p<0.0001, t$ test $)$.

Previous work has suggested that motor learning in the VOR may be less dependent on climbing-fiber-triggered plasticity mechanisms, such as LTD of the parallel fiber-Purkinje cell synapses, when learning is induced using visual-vestibular stimuli at lower sinusoidal frequencies such as $0.5 \mathrm{~Hz}$ (Raymond and Lisberger, 1998; Boyden et al., 2006). We therefore examined motor learning in the $\mathrm{PKC} \gamma^{-/-}$mice using $0.5 \mathrm{~Hz}$ visual-vestibular stimuli but found that they were still profoundly impaired. After $30 \mathrm{~min}$ of $0.5 \mathrm{~Hz}$ gain-up training, wild-type mice showed a sig- 

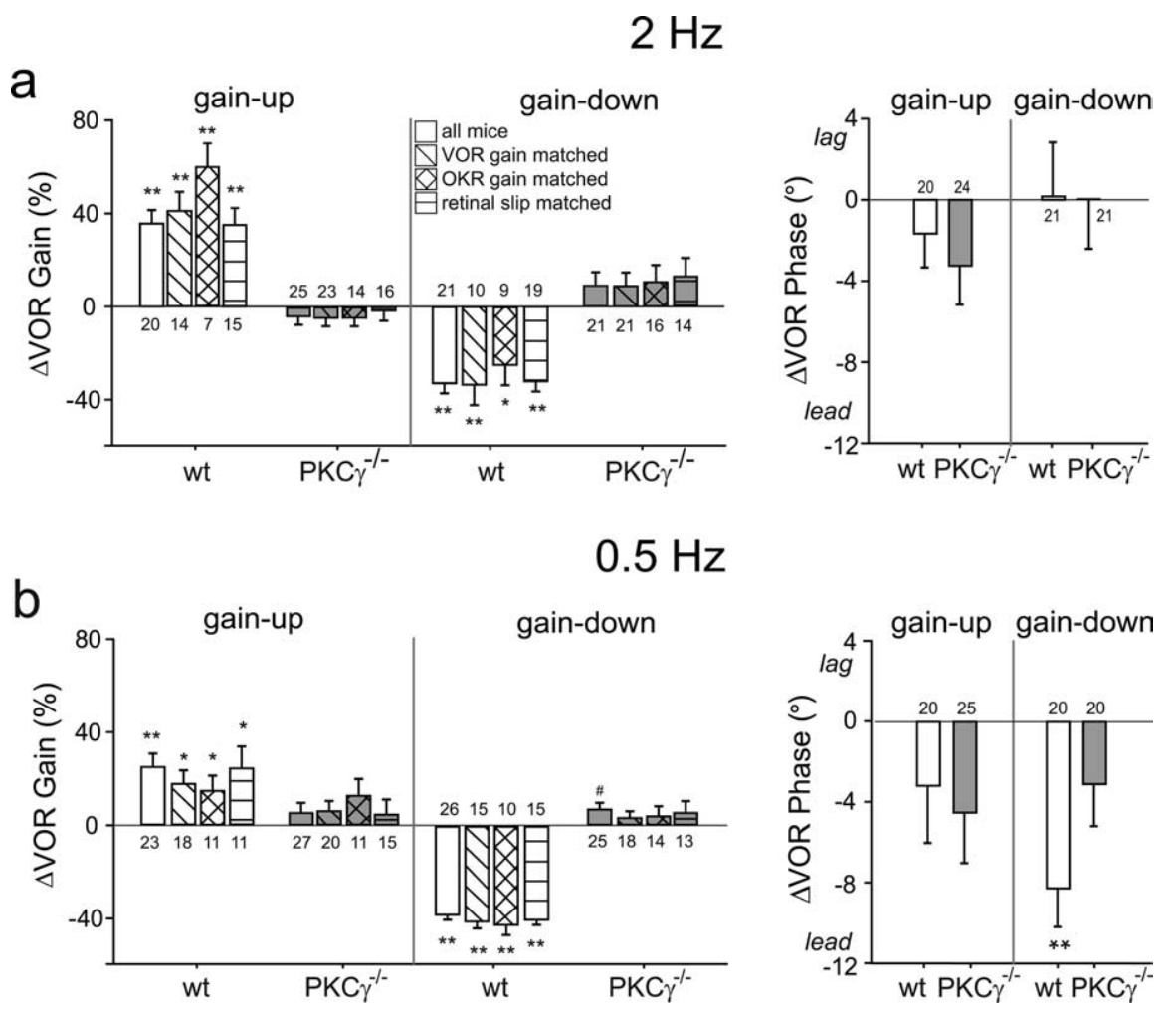

Figure 1. Impaired VOR motor learning in $P K C \gamma^{-/-}$mice. Left, Average percentage change in VOR gain in wild-type (wt; white bars) and $P K C \gamma^{-1-}$ mice (gray bars) after gain-up $(\times 2)$ and gain-down $(\times 0)$ training at $2 \mathrm{~Hz}(\boldsymbol{a})$ and $0.5 \mathrm{~Hz}(\boldsymbol{b})$. Right, Changes in VOR phase induced by each training condition. Open bars indicate data from the full population. Hatched bars are data from subpopulations of wild-type and $P K C \gamma^{-1-}$ mice matched for baseline VOR gain (diagonal hatched bars), baseline OKR gain (cross-hatched bars), or peak speed of retinal slip during training (horizontal hatched bars). Error bars represent SE. Numbers above or below the bars indicate the number of mice in each population or subpopulation. ${ }^{*} p<0.05,{ }^{* *} p<0.01$, one sample $t$ test. ${ }^{\#}<0.05$ significant change in VOR gain but in the maladaptive direction.

nificant increase in VOR gain (Fig. $1 b$, white bars) $(p<0.01)$, but $P K C \gamma^{-1-}$ mice did not exhibit a significant change in VOR gain (Fig. $1 b$, gray bars) ( $p>0.34)$. After $30 \mathrm{~min}$ of $0.5 \mathrm{~Hz}$ gain-down training, wild-type mice showed a significant decrease in VOR gain (Fig. $1 b$, white bars) $(p<0.0001)$, whereas $P K C \gamma^{-1-}$ mice exhibited a significant increase in VOR gain, which is the maladaptive direction (Fig. 1b, gray bars) $(p<0.05)$. For both gain-up and gain-down training at $0.5 \mathrm{~Hz}$, the changes in the $P K C \gamma^{-1-}$ mice were significantly different from wild type $(p<$ $0.01, t$ test). Thus, $P K C \gamma^{-1-}$ mice are impaired in the ability to undergo both learned increases and decreases in VOR gain.

Wild-type mice exhibited a significant increase in VOR phase lead after gain-down training at $0.5 \mathrm{~Hz}$ (Fig. 1b, right, white bars) $(p<0.01)$, as reported in previous studies (Iwashita et al., 2001; Van Alphen and De Zeeuw, 2002; Boyden and Raymond, 2003). This change in phase was absent in $P K C \gamma^{-/-}$mice (Fig. 1b, gray bars) $(p>0.15)$, although the difference between wild-type and $P K C \gamma^{-/-}$mice did not reach statistical significance $(p>0.07, t$ test). Neither wild-type nor $P K C \gamma^{-1-}$ mice exhibited any significant changes in the phase of the VOR after gain-up training at 0.5 $\mathrm{Hz}$ (Fig. $1 b)(p>0.08)$ or after gain-up or gain-down training at $2 \mathrm{~Hz}$ (Fig. 1a) $(p>0.10)$.

Impairment of $P K C \gamma^{-/-}$mice on the learning task cannot be explained by sensory or motor performance deficits

We evaluated whether the impaired VOR motor learning of the $P K C \gamma^{-1-}$ mice reflected an impairment of learning per se, or whether it might be a secondary consequence of sensory or motor performance deficits in the mutants. For animals to exhibit motor learning in the VOR, they must have functional vestibular, visual, and oculomotor systems. The baseline (pretraining) performance of the VOR provides a measure of vestibular and oculomotor functions, and the baseline performance of the OKR provides a measure of visual and oculomotor functions. In the $P K C \gamma^{-1-}$ mice, there were impairments of both the baseline VOR and OKR, but these deficits were not sufficient to account for the learning deficit.

$P K C \gamma^{-1-}$ mice had significantly lower average baseline VOR gains than wildtype mice, measured using a range of head movement frequencies $\left(F_{(1,210)}=40.0\right.$; $p<0.0001$ for genotype, two-factor ANOVA) (Fig. 2a). This was true at each of four frequencies tested, 0.5, 1, 2, and 5 $\mathrm{Hz}(p<0.0125$, Bonferroni-corrected $t$ test). The baseline phase of the VOR also was altered in $P K C \gamma^{-1-}$ mice compared with wild-type mice $\left(F_{(1,209)}=12.9 ; p<\right.$ 0.01) (Fig. 2b), although this difference was only significant when tested at $0.5 \mathrm{~Hz}$ $(p<0.0001)$. Thus, deletion of $P K C \gamma$ affects baseline VOR performance. However, the baseline VOR performance did not appear to be responsible for the learning deficit. For each training condition, there was no significant correlation between the baseline VOR gain of individual mice and their learned changes in VOR gain, in either $P \mathrm{KC}^{-/-}$or wild-type mice (Fig. 3, Table 1). The baseline VOR phase did not significantly correlate with the learned changes in VOR gain either (Table 1). In addition, there was considerable overlap in the baseline performance of the two populations of animals (Fig. 2a,b). Therefore, we compared learning in subpopulations of the $P K C \gamma^{-1-}$ and wild-type mice that had similar distributions of baseline VOR gain (Fig. 3, shaded areas) $(p>0.31$ for each training condition, $t$ test; see Materials and Methods). The results for these subpopulations of mice were similar to those for the full populations: the wild-type mice exhibited adaptive changes in VOR gain for each of the four training conditions tested (gain-up and gaindown training at 0.5 and $2 \mathrm{~Hz}$ ) (Fig. 1, white diagonal hatched bars) $(p<0.05)$, whereas $P K C \gamma^{-1-}$ mice did not exhibit any significant changes in VOR gain (Fig. 1, gray diagonal hatched bars) $(p>0.15)$. Therefore, both the correlation and matched population analyses indicate that impaired motor learning in the $P K C \gamma^{-1-}$ mice cannot be accounted for by their lower average baseline VOR gains.

The OKR performance of the $P K C \gamma^{-/-}$mice was also different from wild-type mice. The OKR gain, measured at $0.5,1$, and $2 \mathrm{~Hz}$, was significantly lower in the $P K C \gamma^{-/-}$mice $\left(F_{(1,137)}=\right.$ $81.1 ; p<0.0001$ for genotype) (Fig. $2 c$ ), and the phase lagged that of wild-type mice $\left(F_{(1,137)}=10.0 ; p<0.01\right)$ (Fig. $\left.2 d\right)$. Nevertheless, there was no significant correlation between the baseline OKR gain or phase of individual mice and their learned changes in VOR gain (Table 1). Moreover, in subpopulations of wild-type and $P K C \gamma^{-1-}$ mice with similar baseline OKR gains $(p>0.13, t$ test), the wild-type mice still exhibited significant changes in 
VOR gain (Fig. 1, white cross-hatched bars) $(p<0.05)$, whereas $P K C \gamma^{-/-}$mice did not (Fig. 1, gray cross-hatched bars) $(p>0.11)$. Thus, the impaired motor learning in the VOR cannot be attributed to the lower average OKR gain or larger OKR phase lag in the $P K C \gamma^{-/-}$mice.

The VOR gain changes in the $P K C \gamma^{-1-}$ mice were significantly different from wild-type mice with matched baseline VOR gain or OKR gain for all training conditions $(p<0.01, t$ test $)$ except gain-up at $0.5 \mathrm{~Hz}(p>0.14)$. The latter reflected a tendency for the VOR gain at $0.5 \mathrm{~Hz}$ to increase in the $P K C \gamma^{-/-}$mice during both gain-up and gain-down training $(p>0.16$, paired $t$ test of gain-up vs gain-down in $n=16$ and $7 P K C \gamma^{-1-}$ mice with baseline VOR or OKR gain, respectively, matched to wild-type mice), which therefore appeared to be nonassociative.

\section{VOR motor learning is impaired for a wide range of retinal slip speeds}

The motion of a visual stimulus on the retina, referred to as retinal slip, is thought to play a key role in the induction of motor learning in the VOR and OKR adaptation. Furthermore, both cerebellar tasks depend on the flocculus and share the same motor output circuitry. A previous study of OKR adaptation in $P K C \gamma^{-/-}$mice revealed an altered dependency of this form of motor learning on the speed of retinal slip, such that OKR adaptation was impaired in $P K C \gamma^{-1-}$ mice when the speed of retinal slip during training was high, but OKR adaptation was completely normal when the speed of retinal slip was low, namely $\leq 2.6 \%$ (Shutoh et al., 2003). Therefore, we examined the retinal slip during each of the training conditions used to induce motor learning in the VOR. Unlike OKR adaptation, motor learning in the VOR was impaired in the $P K C \gamma^{-/-}$ mice even when the speed of retinal slip was low.

During the four training conditions shown in Figure 1, $P K C \gamma^{-/-}$mice experienced retinal slip that was, on the whole, similar to that experienced by wild-type mice. During gain-down training, retinal slip was in the same direction as head movements (close to $0^{\circ}$ ) (Fig. $4 b$ ), and its average peak speed was $<2.6 \%$ at both training frequencies. During gain-up training, both wild-type and $P K C \gamma^{-/-}$ mice experienced peak retinal slip speeds $>10^{\circ} / \mathrm{s}$ in the opposite direction (close to $180^{\circ}$ ) from head movement (Fig. $4 a$ ).

Although the retinal slip experienced by the $P K C \gamma^{-/-}$and wild-type mice was generally similar, there were some differ-
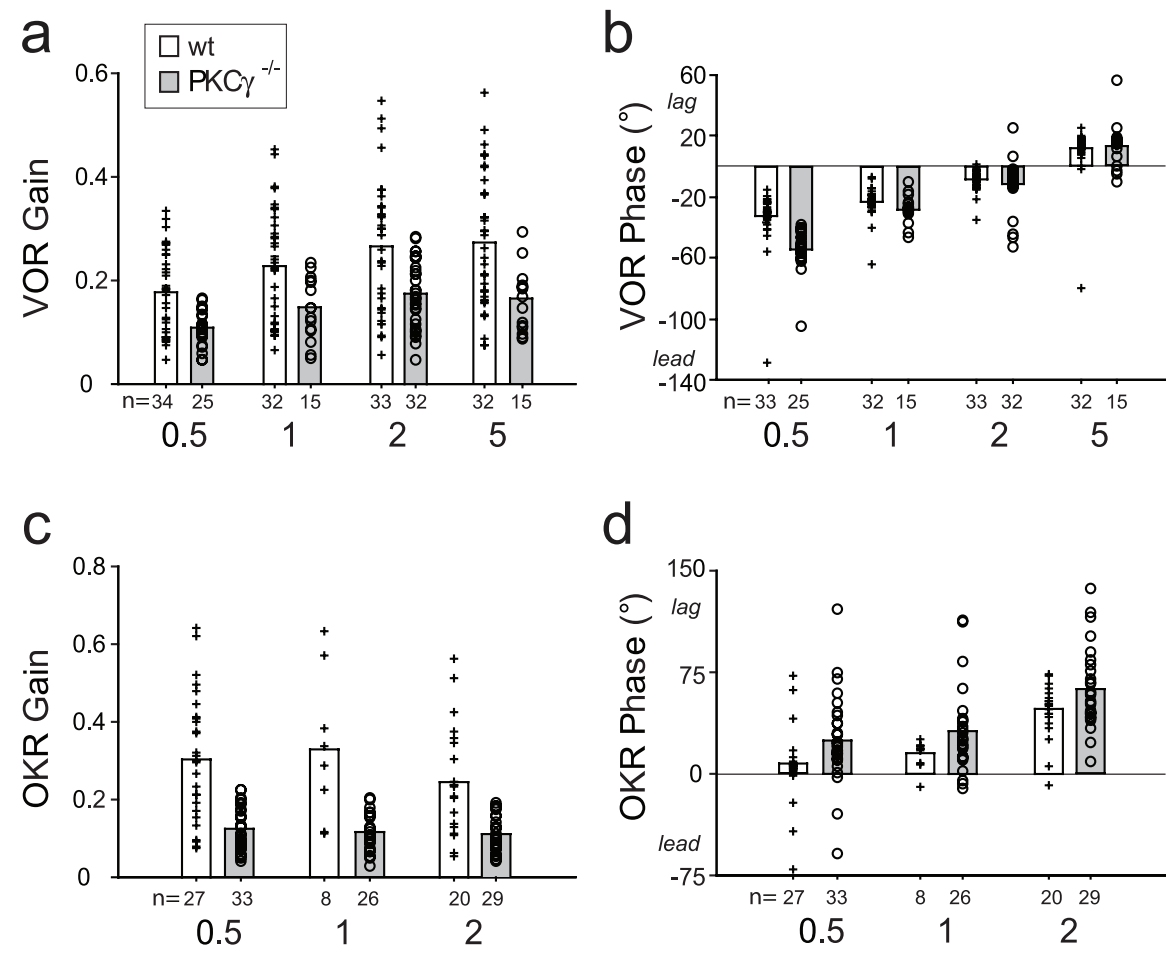

Frequency of Rotation $(\mathrm{Hz})$

Figure 2. The baseline VOR and OKR of $P K C \gamma^{-1-}$ mice are different from those of wild-type mice. Bars represent the average baseline VOR gain $(\boldsymbol{a})$, VOR phase $(\boldsymbol{b})$, OKR gain $(\boldsymbol{c})$, and OKR phase $(\boldsymbol{d})$ in wt $\left(+\right.$, open bars) and $P K C \gamma^{-1-}(\bigcirc$, gray bars) mice measured at different frequencies of head rotation or visual stimulus rotation. Each symbol represents averaged data from one mouse, and the number below each bar indicates the number of mice for each measurement.

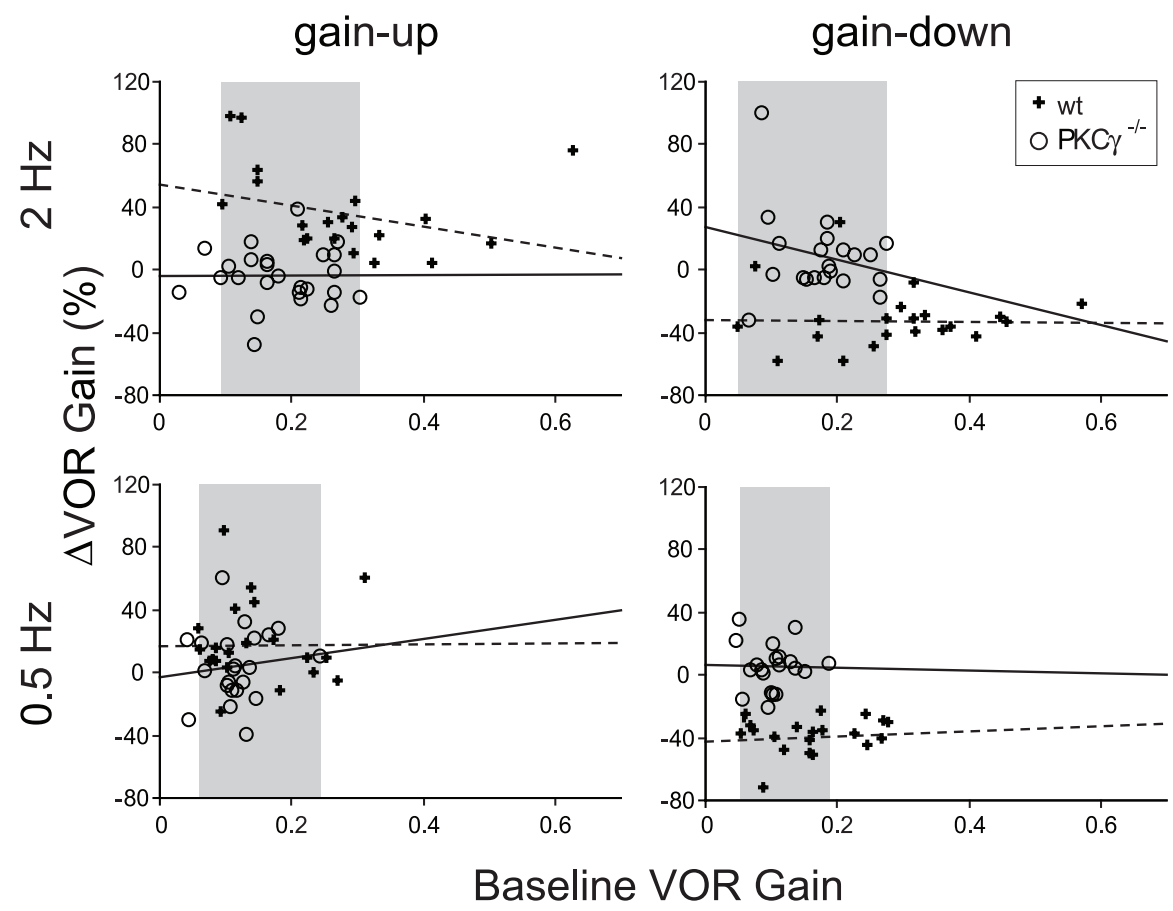

Figure 3. The learned change in VOR gain as a function of the baseline VOR gain of wild-type $(+)$ and $P K C \gamma^{-1-}(\bigcirc)$ mice for each training condition. Each symbol represents data from one mouse. The regression lines for each population of mice are shown: $P K C \gamma^{-/-}$, solid lines; wild-type mice, dashed lines. Shaded areas indicate the ranges of baseline VOR gain in the subpopulation of mice used for comparing learning in wild-type and $P K C \gamma^{-1-}$ mice with similar baseline VOR gains. For number of mice, see Table 1. 
Table 1. Correlation between baseline performance and percentage change in VOR gain

\begin{tabular}{|c|c|c|c|c|c|c|c|c|}
\hline \multirow[b]{2}{*}{ Parameter } & \multicolumn{2}{|c|}{ Gain-up at $2 \mathrm{~Hz}$} & \multicolumn{2}{|c|}{ Gain-down at $2 \mathrm{~Hz}$} & \multicolumn{2}{|c|}{ Gain-up at $0.5 \mathrm{~Hz}$} & \multicolumn{2}{|c|}{ Gain-down at $0.5 \mathrm{~Hz}$} \\
\hline & Wt & $P K C \gamma^{-1-}$ & wt & $P K C \gamma^{-1-}$ & wt & $P K C \gamma^{-1-}$ & wt & $P K C \gamma^{-1-}$ \\
\hline RS max Velocity & $0.28(20)$ & $-0.36(25)$ & $-0.04(21)$ & $-0.50(21)$ & $0.24(18)$ & $-0.28(22)$ & $0.06(22)$ & $-0.18(20)$ \\
\hline RS phase & $-0.38(20)$ & $0.12(25)$ & $0.01(21)$ & $0.12(21)$ & $-0.03(18)$ & $-0.20(22)$ & $-0.13(22)$ & $0.51(20)$ \\
\hline VOR gain & $-0.32(20)$ & $0.01(25)$ & $-0.02(21)$ & $-0.24(21)$ & $0.01(21)$ & $0.12(22)$ & $0.11(21)$ & $-0.02(20)$ \\
\hline VOR phase & $-0.18(20)$ & $0.21(24)$ & $-0.23(21)$ & $-0.13(20)$ & $0.18(20)$ & $0.18(21)$ & $0.58(20)$ & $-0.20(19)$ \\
\hline OKR gain & $-0.54(14)$ & $-0.18(24)$ & $-0.29(15)$ & $\mathbf{0 . 6 1}(19)$ & $-0.01(21)$ & $0.23(18)$ & $0.38(20)$ & $0.46(16)$ \\
\hline OKR phase & $0.15(14)$ & $0.13(24)$ & $-0.14(15)$ & $-0.01(19)$ & $0.30(21)$ & $-0.04(18)$ & $0.20(20)$ & $0.04(16)$ \\
\hline
\end{tabular}

Numbers are correlation coefficients between each parameter and the percentage change in VOR gain for each training condition for wt and $P K C \gamma^{-1-}$ mice. Numbers in parentheses indicate number of mice for each analysis. None of the coefficients are significant when a Bonferroni's correction for multiple comparisons is applied. Without the correction, the coefficients in bold are significant $(p<0.05)$; however, these coefficients have low values, indicating weak correlations, and are scattered throughout the table.

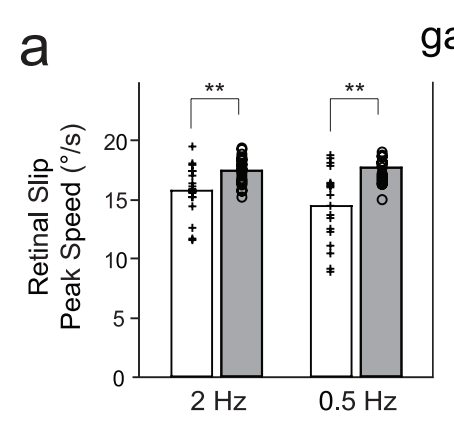

gain-up

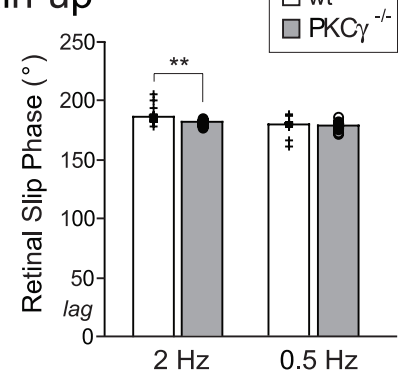

b

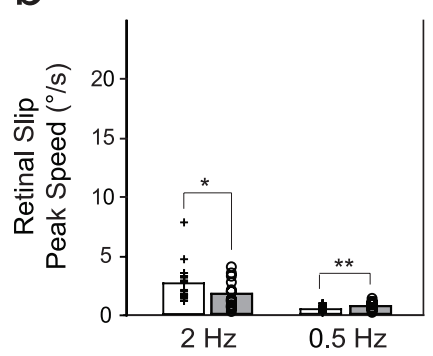

gain-down

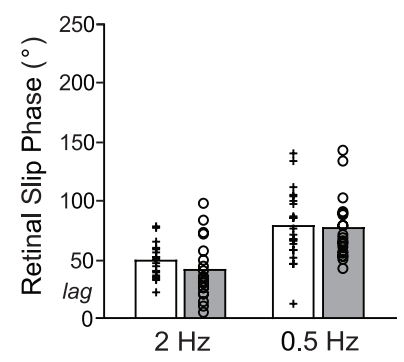

Figure 4. Retinal slip experienced by wild-type and $P K C \gamma^{-/-}$mice during training. Histograms show the average peak speed of retinal slip (left) and average phase of the retinal slip relative to head velocity (right) for wt $\left(+\right.$, white bars) and $P K C \gamma^{-1-}(O$, gray bars) mice during gain-up $(\boldsymbol{a})$ and gain-down $(\boldsymbol{b})$ training at 2 and $0.5 \mathrm{~Hz}$. Each symbol represents data from one mouse. For number of mice, see Table $1 .{ }^{*} p<0.05,{ }^{* *} p<0.01, t$ test.

ences. For the training conditions shown in Figure 1, $P K C \gamma^{-1-}$ mice experienced larger retinal slip speed than wild-type mice, except during $2 \mathrm{~Hz}$ gain-down training, when the retinal slip speed was smaller in $P K C \gamma^{-/-}$mice (Fig. 4) ( $p<0.05, t$ test). To determine whether these differences in retinal slip speed could account for the impaired VOR motor learning in $P K C \gamma^{-1-}$ mice, we compared subpopulations of wild-type and $\mathrm{PKC}^{-/-}$mice with similar peak retinal slip speed for each training condition (see Materials and Methods; $p>0.12, t$ test). We found that, within these subpopulations, wild-type mice still exhibited significant learned changes in VOR gain for each training condition (Fig. 1, white horizontal hatched bars) $(p<0.05)$, whereas $P K C \gamma^{-/-}$mice did not (Fig. 1, gray horizontal hatched bars) $(p>0.14)$. The $P K C \gamma^{-1-}$ mice were significantly different from wild-type mice matched for retinal slip for all training conditions $(p<0.01, t$ test $)$ except for gain-up training at $0.5 \mathrm{~Hz}(p>0.07)$, again reflecting the tendency for $P K C \gamma^{-1-}$ mice to increase their VOR gain regardless of training condition at $0.5 \mathrm{~Hz}(p>0.11$, paired $t$ test; $n=8$ ).

In Figure 4, the retinal slip shown is the average across the population of mice. Across individual wild-type and $P K C \gamma^{-/-}$ mice, the retinal slip speed and the percentage change in VOR gain were not significantly correlated for any training condition (Table 1). There were also no significant correlations between the phase of the retinal slip and motor learning (Table 1).

To test VOR motor learning of $P K C \gamma^{-1-}$ mice across a broader range of retinal slip speeds, we used several additional training conditions $(\times 0.25, \times 0.5, \times 0.75, \times 1.25, \times 1.5$, and $\times 1.75$; see Materials and Methods). Figure 5, $a$ and $c$, plots the average peak retinal slip velocity for each training condition and the corresponding average learned change in VOR gain for the population. Figure 5, $b$ and $d$, plots the peak retinal slip velocity and the corresponding learned change in VOR gain from individual mice. The different training conditions produced a wide range of retinal slip velocities, but none induced a significant change in VOR gain in the $P K C \gamma^{-/-}$mice $(p>0.32$, one sample $t$ test). These results confirm that the impairment of VOR motor learning in these mice is independent of retinal slip velocity.

Three different analyses (Table 1, Figs. 1, 5) all lead to the same conclusion: the impaired VOR motor learning of $P \mathrm{KC}^{-/-}$mice cannot be explained by the retinal slip experienced during training. Furthermore, the same range of low retinal slip speeds that supported intact OKR adaptation failed to support VOR motor learning in these mice.

\section{Discussion}

Motor learning in the VOR is profoundly impaired in $P K C \gamma^{-/-}$ mice. This impairment could not be accounted for by the retinal slip present during training, the baseline VOR, or the baseline visual or oculomotor function of these mice. Hence, impairment on this task appears to result from perturbation of the neural processes involved in motor learning per se rather than a secondary consequence of a sensory or motor performance deficit.

Previously, it was shown that nonspecific inhibition of all PKC isoforms in Purkinje cells, by expression of a transgene for a peptide inhibitor of PKC (L7-PKCI), profoundly impairs VOR motor learning (De Zeeuw et al., 1998b). In those L7-PKCI mice, it was reported that no multiple climbing fiber innervation was present in adults, perhaps because of incomplete inhibition of PKC $\gamma$ by the transgene (Goossens et al., 2001; Ghoumari et al., 2002). The learning impairment in the L7-PKCI mice was attributed to the documented impairment of LTD at the parallel fiber to Purkinje cell synapses (pf-Pk LTD) in those mice. In contrast, specific deletion of the $\gamma$ isoform of PKC results in multiple climbing fiber innervation in adult mice and no disruption of pf-Pk LTD (Chen et al., 1995; Kano et al., 1995). Despite extensive analysis, no other disruption of the cerebellar circuit has been identified in the $P K C \gamma^{-1-}$ mice, apart from the multiple climbing fiber innervation of Purkinje cells. The dendritic arborization of cultured Purkinje cells from $P K C \gamma^{-/-}$mice is slightly en- 
larged, although this has not been confirmed in vivo (Kano et al., 1995; Schrenk et al., 2002). Within the cerebellar cortex and its targets, PKC $\gamma$ is expressed only in Purkinje cells (Garcia and Harlan, 1997; Barmack et al., 2000; Shutoh et al., 2003). Therefore, although other mechanisms cannot be ruled out, it is likely that the altered cerebellumdependent learning in the $P K C \gamma^{-/-}$ mice reflects the multiple climbing fiber innervation of Purkinje cells.

The multiple climbing fiber innervation of Purkinje cells could perturb several forms of climbing fiber-related plasticity in vivo. Climbing fibers regulate the induction of both LTD and LTP at the parallel fiber-to-Purkinje cell synapses (Coesmans et al., 2004). Also, the synapses from climbing fibers to Purkinje cells undergo homosynaptic LTD, and this LTD is PKC dependent, although it is not known which PKC isoform is involved (Hansel and Linden, 2000). In addition, climbing fiber activity has been shown to regulate the frequency and pattern of $\mathrm{Na}^{+}$spike ("simple spike") firing in Purkinje cells, which could influence the induction of plasticity at the synapses of the Purkinje cells or at downstream sites (Loewenstein et al., 2005; McKay et al., 2007). Finally, the calcium transients associated with surplus climbing fiber synapses are more restricted to the proximal dendrites of the Purkinje cell than the calcium transients associated with normal climbing fiber inputs, and this may alter their function (Hashimoto and Kano, 2003).

Although eyeblink conditioning, the rotorod task, and motor learning in the OKR and VOR all depend on the cerebellum, the deletion of PKC $\gamma$ had different effects on each form of motor learning. Therefore, the usage of climbing fiber-dependent plasticity mechanisms and hence the effect of multiple climbing fiber innervation may vary significantly across these tasks.

\section{Extracerebellar effects of $P K C \gamma$ deletion}

Delay eyeblink conditioning is enhanced in the $P K C \gamma^{-1-}$ mice, whereas the other three cerebellum-dependent tasks that have been tested are impaired (Chen et al., 1995; Shutoh et al., 2003) (Fig. 1). Extracerebellar effects of PKC $\gamma$ deletion could contribute to this difference. In the VOR and OKR circuit, PKC $\gamma$ is not expressed anywhere except in Purkinje cells. In contrast, PKC $\gamma$ is expressed in the hippocampus, and, in rodents, lesions of the hippocampus facilitate the acquisition of delay eyeblink conditioning (Lee and Kim, 2004). $P K C \gamma^{-1-}$ mice have deficits in hippocampal function that may, like a surgical lesion, facilitate eyeblink conditioning (Abeliovich et al., 1993a,b). The hippocampus is not thought to contribute to OKR and VOR adaptation. Hence, the difference between eyeblink and oculomotor learning in $P K C \gamma^{-/-}$mice could reflect an extracerebellar effect on eyeblink conditioning.
$2 \mathrm{~Hz}$

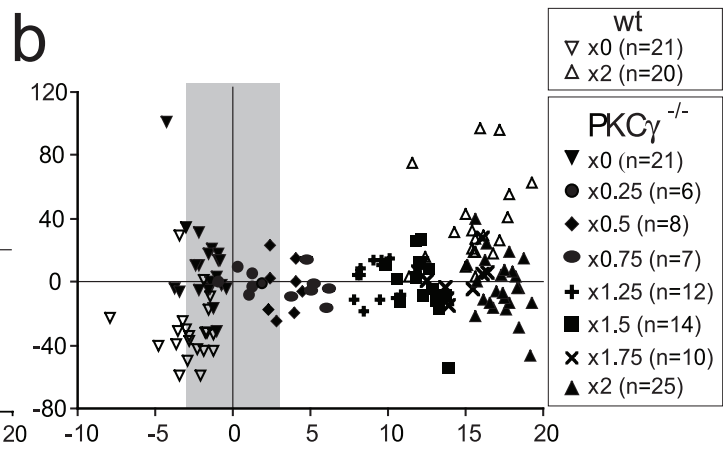

\section{$0.5 \mathrm{~Hz}$}

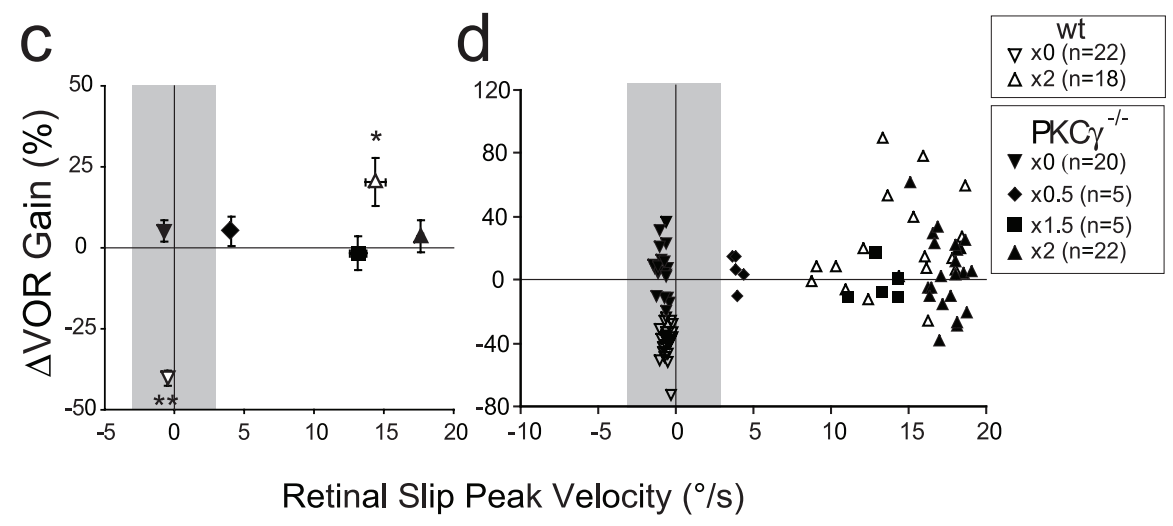

Figure 5. $P K C \gamma^{-1-}$ mice are impaired in VOR motor learning regardless of the retinal slip velocity. Average percentage change in the VOR gain plotted as a function of the average peak retinal slip velocity for each training condition for $2 \mathrm{~Hz}$ (a) and $0.5 \mathrm{~Hz}$ (c)

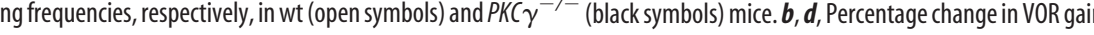
data from one mouse. Positive velocity values indicate that the retinal slip velocity is in the same direction as the eye velocity, and negative values indicate that the retinal slip velocity is in the opposite direction. Gray areas indicate peak retinal slip velocities between -3 and $+3 \%$ s. Error bars indicate SE. ${ }^{*} p<0.05$ and ${ }^{* *} p<0.0001$, one-sample $t$ test.

Inhibitory and excitatory signaling in cerebellar circuits A second factor that could contribute to the variable effects of $P K C \gamma$ deletion across the different cerebellum-dependent learning tasks is the organization of the relevant neural circuits downstream of the cerebellar cortex and, in particular, how activity in the cerebellar cortex influences performance of the learned behavior.

During eyeblink conditioning, Purkinje cells develop an inhibitory response to the conditioned stimulus (Kotani et al., 2006; Jirenhed et al., 2007). This conditioned decrease in Purkinje cell firing below the spontaneous rate should disinhibit the target neurons of the Purkinje cells in the interpositus nucleus, which drive the production of the conditioned blink responses. The conditioned inhibitory response in the Purkinje cells has been attributed to pf-Pk LTD, and Chen et al. (1995) suggested that the facilitated eyeblink conditioning in $P K C \gamma^{-1-}$ mice reflects enhanced $\mathrm{pf}-\mathrm{Pk}$ LTD. If multiple climbing fiber innervation enhances the induction of pf-Pk LTD in vivo, that could lead to an enhanced inhibitory response of the Purkinje cells to the conditioned stimulus, enhanced disinhibition of interpositus neurons, and hence facilitation of blink responses (i.e., enhanced eyeblink conditioning). Likewise, because climbing fiber activity can suppress simple spike activity in the Purkinje cells (Colin et al., 1980; Demer et al., 1985; Luebke and Robinson, 1994), any 
enhancement in the rate of climbing fiber input to the Purkinje cells attributable to multiple climbing fiber innervation could suppress spontaneous simple spiking in the Purkinje cells, which would also disinhibit the interpositus nucleus and facilitate the production of blinks.

Studies of several lines of mutant mice that lack pf-Pk LTD have provided evidence for a role of $\mathrm{pf}-\mathrm{Pk} \mathrm{LTD}$, not just in eyeblink conditioning, but also OKR adaptation, motor learning in the VOR, and the rotorod task (Chen et al., 1996; Kishimoto et al., 2001; Shutoh et al., 2002; Koekkoek et al., 2003; Katoh et al., 2005). However, enhanced pf-Pk LTD would not necessarily enhance performance on these tasks. In the eyeblink circuit, one might expect that anything that decreases Purkinje cell firing could facilitate production of the blink. In contrast, VOR and OKR performance and learning use both decreased and increased firing rate signals in the Purkinje cells and their target neurons in the vestibular nuclei. During the VOR and OKR, activity in the left vestibular nucleus increases for rightward eye movements and decreases for leftward eye movements, whereas activity in the right vestibular nucleus increases for leftward eye movements and decreases for rightward eye movements (Lisberger et al., 1994). Because of this push-pull arrangement of the oculomotor circuitry, a general, bilateral suppression of activity in Purkinje cells and disinhibition of the vestibular nuclei would not necessarily facilitate the VOR or OKR responses or the learning-related changes in those responses. Furthermore, disinhibition of the target neurons of the Purkinje cells could put those downstream neurons out of the dynamic range that is optimal for learning. For such tasks, an optimal amount of pf-Pk LTD may be required for learning (Koekkoek et al., 2005), and enhanced pf-Pk LTD may impair learning. Thus, enhanced LTD may not always facilitate learning but sometimes facilitate and sometimes impair cerebellum-dependent learning, depending on the circuit level organization. More broadly, we expect that VOR motor learning, OKR adaptation, and rotorod tasks depend on the appropriate balance of pf-Pk LTD and LTP. Recently, it has been shown that climbing fiber activity can suppress pf-Pk LTP (Van Beugen et al., 2006); therefore, the appropriate balance of pf-Pk LTP and LTD may be disrupted by multiple climbing fiber innervation of Purkinje cells.

\section{The timing demands are different between cerebellar tasks}

Several factors discussed above, including region-specific effects of PKC $\gamma$ deletion within the cerebellum, extracerebellar effects of PKC $\gamma$ deletion, and organization of the relevant circuits downstream of the cerebellar cortex, could contribute to the different effects of PKC $\gamma$ deletion on eyeblink conditioning compared with the other tasks that have been tested. However, none of these factors can account for the difference between the two oculomotor learning tasks. OKR adaptation and motor learning in the VOR both depend on the same cerebellar region and share much of the same extracerebellar circuitry (De Zeeuw et al., 1998a). Nevertheless, motor learning in the VOR is considerably more impaired. OKR adaptation was intact for slower retinal slip speeds, whereas motor learning in the VOR was impaired across the whole range of retinal slip speeds tested, including speeds at which OKR adaptation was normal (Shutoh et al., 2003). This discrepancy must arise from other differences in the features of the tasks.

One difference among the four learning tasks that correlates with the extent to which they are impaired in the $P K C \gamma^{-/-}$mice is their temporal requirements. The VOR is a very fast reflex, with a latency of $\sim 10 \mathrm{~ms}$, good function at head rotation frequencies up to $25 \mathrm{~Hz}$ or higher (Lisberger, 1984; Huterer and Cullen, 2002; Ramachandran and Lisberger, 2005), and adaptive changes in the VOR response at frequencies up to at least $25 \mathrm{~Hz}$ (Raymond and Lisberger, 1996; Ramachandran and Lisberger, 2005). It is difficult to quantify the temporal requirements of the complex movements measured by the rotorod task, but it is reasonable to assume they also are fast. In contrast, the OKR is much slower, with a latency of $\sim 70$ or higher (Haddad et al., 1980; Marsh and Baker, 1997; Van Alphen et al., 2001) and with the gain of the response falling off at frequencies above $\sim 1 \mathrm{~Hz}$ (Godaux et al., 1983; Schweigart et al., 1997; Iwashita et al., 2001; Beck et al., 2004; Katoh et al., 2007). The temporal requirements of eyeblink conditioning are even less stringent. Conditioning does not occur at interstimulus intervals (ISI) much less than $150 \mathrm{~ms}$. Although the blink response is timed to occur around the time of the unconditioned stimulus, the onset latency is $\sim 125 \mathrm{~ms}$ after onset of the conditioned stimulus, even for the shortest effective ISIs (Schneiderman and Gormezano, 1964; Smith et al., 1969; Mauk and Ruiz, 1992). In addition, the peak of the conditioned response can occur anywhere between $80 \mathrm{~ms}$ before to $50 \mathrm{~ms}$ after the time point at which the onset of the unconditioned stimulus occurred during training (Schneiderman and Gormezano, 1964; Smith et al., 1969; Mauk and Ruiz, 1992; Perrett et al., 1993; Ivkovich and Thompson, 1997; Gruart et al., 2000; Ivarsson and Svensson, 2000; Bao et al., 2002; Lee and Kim, 2004). Thus, in the $P K C \gamma^{-1-}$ mice, the learning tasks with the highest temporal demands (rotorod and motor learning in the VOR) were most impaired, and those with lower temporal demands (OKR adaptation and eyeblink conditioning) were least impaired. Hence, multiple climbing fiber innervation may disrupt the temporal precision of signaling necessary for learning.

\section{General conclusion}

Although eyeblink conditioning, the rotorod task, and motor learning in the OKR and VOR all depend on the cerebellum, the deletion of $P K C \gamma$ had different effects on each form of motor learning. Therefore, the usage of climbing fiber-dependent plasticity mechanisms and hence the effect of multiple climbing fiber innervation may vary significantly across these tasks. The finding of different effects of $P K C \gamma$ deletion on different cerebellumdependent learning tasks is consistent with recent studies that suggested that there is more than one way to store memories in the cerebellum and that different components of motor learning depend on different signaling pathways in the cerebellum and related circuitry (Boyden et al., 2006; Hansel et al., 2006). Likewise, mutants with impaired hippocampal LTP have impaired learning for some, but intact learning for other, hippocampusdependent learning tasks (Reisel et al., 2002; Bannerman et al., 2003). A better understanding of such differences in the performance of mutants on tasks that depend on the same brain structure or circuits are likely to yield fundamental insights into circuit level properties of learning. The current results provide a step in this direction by identifying the organization of relevant extracerebellar circuitry and the precision of timing required for each task as circuit-level organizational features that could influence the usage of particular plasticity mechanisms in the cerebellum.

\section{References}

Abeliovich A, Chen C, Goda Y, Silva AJ, Stevens CF, Tonegawa S (1993a) Modified hippocampal long-term potentiation in $\mathrm{PKC} \gamma$-mutant mice. Cell 75:1253-1262.

Abeliovich A, Paylor R, Chen C, Kim JJ, Wehner JM, Tonegawa S (1993b) 
PKC $\gamma$ mutant mice exhibit mild deficits in spatial and contextual learning. Cell 75:1263-1271.

Albus JS (1971) A theory of cerebellar function. Math Biosci 10:25-61.

Bannerman DM, Deacon RM, Seeburg PH, Rawlins JN (2003) GluR-ADeficient mice display normal acquisition of a hippocampus-dependent spatial reference memory task but are impaired during spatial reversal. Behav Neurosci 117:866-870.

Bao S, Chen L, Kim JJ, Thompson RF (2002) Cerebellar cortical inhibition and classical eyeblink conditioning. Proc Natl Acad Sci USA 99:1592-1597.

Bareggi R, Narducci P, Grill V, Lach S, Martelli AM (1996) Selective distribution of multiple protein kinase $\mathrm{C}$ isoforms in mouse cerebellar cortex. Biol Cell 87:55-63.

Barmack NH, Qian Z, Yoshimura J (2000) Regional and cellular distribution of protein kinase $\mathrm{C}$ in rat cerebellar Purkinje cells. J Comp Neurol 427:235-254.

Beck JC, Gilland E, Tank DW, Baker R (2004) Quantifying the ontogeny of optokinetic and vestibuloocular behaviors in zebrafish, medaka, and goldfish. J Neurophysiol 92:3546-3561.

Ben-Shlomo H, Sigmund O, Stabel S, Reiss N, Naor Z (1991) Preferential release of catecholamine from permeabilized PC12 cells by alpha- and beta-type protein kinase C subspecies. Biochem J 280:65-69.

Boyden ES, Raymond JL (2003) Active reversal of motor memories reveals rules governing memory encoding. Neuron 39:1031-1042.

Boyden ES, Katoh A, Pyle JL, Chatila TA, Tsien RW, Raymond JL (2006) Selective engagement of plasticity mechanisms for motor memory sorage. Neuron 51:823-834.

Brandon NJ, Uren JM, Kittler JT, Wang H, Olsen R, Parker PJ, Moss SJ (1999) Subunit-specific association of protein kinase $C$ and the receptor for activated C kinase with GABA type A receptors. J Neurosci 19:9228-9234.

Cambray-Deakin M, Adu J, Burgoyne R (1990) Neuritogenesis in cerebellar granule cells in vitro: a role for protein kinase C. Brain Res Dev Brain Res 53:40-46.

Chen C, Kano M, Abeliovich A, Chen L, Bao S, Kim J, Hashimoto K, Thompson RF, Tonegawa S (1995) Impaired motor coordination correlates with persistent multiple climbing fiber innervation in PKC $\gamma$ mutant mice. Cell 83:1233-1242.

Chen L, Bao S, Lockard J, Kim J, Thompson R (1996) Impaired classical eyeblink conditioning in cerebellar-lesioned and Purkinje cell degeneration (pcd) mutant mice. J Neurosci 16:2829-2838.

Coesmans M, Weber JT, De Zeeuw CI, Hansel C (2004) Bidirectional parallel fiber plasticity in the cerebellum under climbing fiber control. Neuron 44:691-700.

Coffey E, Sihra T, Nicholls D (1993) Protein kinase C and the regulation of glutamate exocytosis from cerebrocortical synaptosomes. J Biol Chem 268:21060-21065.

Colin F, Manil J, Desclin JC (1980) The olivocerebellar system. I. Delayed and slow inhibitory effects: an overlooked salient feature of cerebellar climbing fibers. Brain Res 187:3-27.

De Zeeuw CI, van Alphen AM, Koekkoek SK, Buharin E, Coesmans M, Morpurgo MM, van den Burg J (1998a) Recording eye movements in mice: a new approach to investigate the molecular basis of cerebellar control of motor learning and motor timing. Otolaryngol Head Neck Surg 119:193-203.

De Zeeuw CI, Hansel C, Bian F, Koekkoek SK, van Alphen AM, Linden DJ, Oberdick J (1998b) Expression of a protein kinase C inhibitor in Purkinje cells blocks cerebellar LTD and adaptation of the vestibulo-ocular reflex. Neuron 20:495-508.

Demer JL, Echelman DA, Robinson DA (1985) Effects of electrical stimulation and reversible lesions of the olivocerebellar pathway on Purkinje cell activity in the flocculus of the cat. Brain Res 346:22-31.

Eccles JC, Ito M, Szentagothai J (1967) The cerebellum as a neuronal learning machine. Berlin: Springer.

Eilers J, Takechi H, Finch EA, Augustine GJ, Konnerth A (1997) Local dendritic $\mathrm{Ca}^{2+}$ signaling induces cerebellar long-term depression. Learn Mem 4:159-168.

Fan H-Y, Tong C, Li M-Y, Lian L, Chen D-Y, Schatten H, Sun Q-Y (2002) Translocation of the classic protein kinase $\mathrm{C}$ isoforms in porcine oocytes: implications of protein kinase $\mathrm{C}$ involvement in the regulation of nuclear activity and cortical granule exocytosis. Exp Cell Res 277:183-191.
Garcia MM, Harlan RE (1997) Protein kinase C in central vestibular, cerebellar, and precerebellar pathways of the rat. J Comp Neurol 385:26-42.

Gerwig M, Hajjar K, Dimitrova A, Maschke M, Kolb FP, Frings M, Thilmann AF, Forsting M, Diener HC, Timmann D (2005) Timing of conditioned eyeblink responses is impaired in cerebellar patients. J Neurosci 25:3919-3931.

Ghoumari AM, Wehrle R, De Zeeuw CI, Sotelo C, Dusart I (2002) Inhibition of protein kinase $\mathrm{C}$ prevents Purkinje cell death but does not affect axonal regeneration. J Neurosci 22:3531-3542.

Gilbert PF, Thach WT (1977) Purkinje cell activity during motor learning. Brain Res 128:309-328.

Godaux E, Gobert C, Halleux J (1983) Vestibuloocular reflex, optokinetic response, and their interactions in the alert cat. Exp Neurol 80:42-54.

Goossens J, Daniel H, Rancillac A, van der Steen J, Oberdick J, Crepel F, De Zeeuw CI, Frens MA (2001) Expression of protein kinase C inhibitor blocks cerebellar long-term depression without affecting Purkinje cell excitability in alert mice. J Neurosci 21:5813-5823.

Gruart A, Schreurs BG, Dominguez del Toro E, Delgado-Garcia JM (2000) Kinetic and frequency-domain properties of reflex and conditioned eyelid responses in the rabbit. J Neurophysiol 83:836-852.

Gundlfinger A, Kapfhammer J, Kruse F, Leitges M, Metzger M (2003) Different regulation of Purkinje cell dendritic development in cerebellar slice cultures by protein kinase C alpha and beta. J Neurobiol 57:95-109.

Haddad GM, Demer JL, Robinson DA (1980) The effect of lesions of the dorsal cap of the inferior olive on the vestibulo-ocular and optokinetic systems of the cat. Brain Res 185:265-275.

Hansel C, Linden DJ (2000) Long-term depression of the cerebellar climbing fiber-Purkinje neuron synapse. Neuron 26:473-482.

Hansel C, de Jeu M, Belmeguenai A, Houtman SH, Buitendijk GH, Andreev D, De Zeeuw CI, Elgersma Y (2006) $\alpha$ CaMKII is essential for cerebellar LTD and motor learning. Neuron 51:835-843.

Hartell NA (1996) Strong activation of parallel fibers produces localized calcium transients and a form of LTD that spreads to distant synapses. Neuron 16:601-610.

Hashimoto K, Kano M (2003) Functional differentiation of multiple climbing fiber inputs during synapse elimination in the developing cerebellum. Neuron 38:785-796.

Hashimoto T, Ase K, Sawamura S, Kikkawa U, Saito N, Tanaka C, Nishizuka Y (1988) Postnatal development of a brain-specific subspecies of protein kinase C in rat. J Neurosci 8:1678-1683.

Hesslow G, Ivarsson M (1996) Inhibition of the inferior olive during conditioned responses in the decerebrate ferret. Exp Brain Res 110:36-46.

Huang F, Young W, Yoshida Y, Huang K (1990) Developmental expression of protein kinase $\mathrm{C}$ isozymes in rat cerebellum. Brain Res Dev Brain Res 52:121-130.

Huterer M, Cullen KE (2002) Vestibuloocular reflex dynamics during highfrequency and high-acceleration rotations of the head on body in Rhesus monkey. J Neurophysiol 88:13-28.

Ito M (1972) Neural design of the cerebellar motor control system. Brain Res 40:81-84.

Ito M, Sakurai M, Tongroach P (1982a) Climbing fibre induced depression of both mossy fibre responsiveness and glutamate sensitivity of cerebellar Purkinje cells. J Physiol (Lond) 324:113-134.

Ito M, Jastreboff PJ, Miyashita Y (1982b) Specific effects of unilateral lesions in the flocculus upon eye movements in albino rabbits. Exp Brain Res 42:233-242.

Ivarsson M, Svensson P (2000) Conditioned eyeblink response consists of two distinct components. J Neurophysiol 83:796-807.

Ivkovich D, Thompson RF (1997) Motor cortex lesions do not affect learning or performance of the eyeblink response in rabbits. Behav Neurosci 111:727-738.

Iwashita M, Kanai R, Funabiki K, Matsuda K, Hirano T (2001) Dynamic properties, interactions and adaptive modifications of vestibulo-ocular reflex and optokinetic response in mice. Neurosci Res 39:299-311.

Jirenhed D-A, Bengtsson F, Hesslow G (2007) Acquisition, extinction, and reacquisition of a cerebellar cortical memory trace. J Neurosci 27:2493-2502.

Jorntell H, Ekerot CF (2002) Reciprocal bidirectional plasticity of parallel fiber receptive fields in cerebellar Purkinje cells and their afferent interneurons. Neuron 34:797-806.

Judge SJ, Richmond BJ, Chu FC (1980) Implantation of magnetic search 
coils for measurement of eye position: an improved method. Vision Res 20:535-538.

Kano M, Hashimoto K, Chen C, Abeliovich A, Aiba A, Kurihara H, Watanabe $\mathrm{M}$, Inoue $\mathrm{Y}$, Tonegawa S (1995) Impaired synapse elimination during cerebellar development in PKC gamma mutant mice. Cell 83:1223-1231.

Katoh A, Kitazawa H, Itohara S, Nagao S (1998) Dynamic characteristics and adaptability of mouse vestibulo-ocular and optokinetic response eye movements and the role of the flocculo-olivary system revealed by chemical lesions. Proc Natl Acad Sci USA 95:7705-7710.

Katoh A, Yoshida T, Himeshima Y, Mishina M, Hirano T (2005) Defective control and adaptation of reflex eye movements in mutant mice deficient in either the glutamate receptor 2 subunit or Purkinje cells. Eur J Neurosci 21:1315-1326.

Katoh A, Jindal JA, Raymond JL (2007) Motor deficits in homozygous and heterozygous P/Q-type calcium channel mutants. J Neurophysiol 97:1280-1287.

Kim JJ, Krupa DJ, Thompson RF (1998) Inhibitory cerebello-olivary projections and blocking effect in classical conditioning. Science 279:570-573.

Kimpo RR, Boyden ES, Katoh A, Ke MC, Raymond JL (2005) Distinct patterns of stimulus generalization of increases and decreases in VOR gain. J Neurophysiol 94:3092-3100.

Kishimoto Y, Kawahara S, Fujimichi R, Mori H, Mishina M, Kirino Y (2001) Impairment of eyeblink conditioning in GluRdelta2-mutant mice depends on the temporal overlap between conditioned and unconditioned stimuli. Eur J Neurosci 14:1515-1521.

Koekkoek SK, van Alphen AM, van den Burg J, Grosveld F, Galjart N, De Zeeuw CI (1997) Gain adaptation and phase dynamics of compensatory eye movements in mice. Genes Funct 1:175-190.

Koekkoek SK, Hulscher HC, Dortland BR, Hensbroek RA, Elgersma Y, Ruigrok TJ, De Zeeuw CI (2003) Cerebellar LTD and learningdependent timing of conditioned eyelid responses. Science 301: $1736-1739$.

Koekkoek SKE, Yamaguchi K, Milojkovic BA, Dortland BR, Ruigrok TJH, Maex R, De Graaf W, Smit AE, VanderWerf F, Bakker CE (2005) Deletion of FMR1 in Purkinje cells enhances parallel fiber LTD, enlarges spines, and attenuates cerebellar eyelid conditioning in Fragile X syndrome. Neuron 47:339-352.

Kotani S, Kawahara S, Kirino Y (2006) Purkinje cell activity during classical eyeblink conditioning in decerebrate guinea pigs. Brain Res 1068:70-81.

Le Marec N, Lalonde R (1997) Sensorimotor learning and retention during equilibrium tests in Purkinje cell degeneration mutant mice. Brain Res $768: 310-316$.

Lee T, Kim JJ (2004) Differential effects of cerebellar, amygdalar, and hippocampal lesions on classical eyeblink conditioning in rats. J Neurosci 24:3242-3250.

Leitges M, Kovac J, Plomann M, Linden DJ (2004) A unique PDZ ligand in $\mathrm{PKC} \alpha$ confers induction of cerebellar long-term synaptic depression. Neuron 44:585-594.

Lisberger SG (1984) The latency of pathways containing the site of motor learning in the monkey vestibulo-ocular reflex. Science 225:74-76.

Lisberger SG, Miles FA, Zee DS (1984) Signals used to compute errors in monkey vestibuloocular reflex: possible role of flocculus. J Neurophysiol 52:1140-1153.

Lisberger SG, Pavelko TA, Broussard DM (1994) Responses during eye movements of brain stem neurons that receive monosynaptic inhibition from the flocculus and ventral paraflocculus in monkeys. J Neurophysiol 72:909-927.

Loewenstein Y, Mahon S, Chadderton P, Kitamura K, Sompolinsky H, Yarom Y, Hausser M (2005) Bistability of cerebellar Purkinje cells modulated by sensory stimulation 8:202-211.

Luebke AE, Robinson DA (1994) Gain changes of the cat's vestibulo-ocular reflex after flocculus deactivation. Exp Brain Res 98:379-390.

Marr D (1969) A theory of cerebellar cortex. J Physiol (Lond) 202:437-470.

Marsh E, Baker R (1997) Normal and adapted visuooculomotor reflexes in goldfish. J Neurophysiol 77:1099-1118.

Martin WJ, Malmberg AB, Basbaum AI (2001) PKC $\gamma$ contributes to a subset of the NMDA-dependent spinal circuits that underlie injury-induced persistent pain. J Neurosci 21:5321-5327.

Mauk MD, Ruiz BP (1992) Learning-dependent timing of Pavlovian eyelid responses: differential conditioning using multiple interstimulus intervals. Behav Neurosci 106:666-681.
Mauk MD, Steinmetz JE, Thompson RF (1986) Classical conditioning using stimulation of the inferior olive as the unconditioned stimulus. Proc Natl Acad Sci USA 83:5349-5353.

McElligott JG, Beeton P, Polk J (1998) Effect of cerebellar inactivation by lidocaine microdialysis on the vestibuloocular reflex in goldfish. J Neurophysiol 79:1286-1294.

McKay BE, Engbers JD, Mehaffey WH, Gordon GRJ, Molineux ML, Bains JS, Turner RW (2007) Climbing fiber discharge regulates cerebellar functions by controlling the intrinsic characteristics of Purkinje cell output. J Neurophysiol 97:2590-2604.

Moriya M, Tanaka S (1994) Prominent expression of protein kinase C $\gamma$ mRNA in the dendrite-rich neuropil of mice cerebellum at the critical period for synaptogenesis. NeuroReport 5:929-932.

Nagao S (1983) Effects of vestibulocerebellar lesions upon dynamic characteristics and adaptation of the vestibulo-ocular and optokinetic responses in pigmented rabbits. Exp Brain Res 53:36-46.

Nishiyama H, Linden DJ (2004) Differential maturation of climbing fiber innervation in cerebellar vermis. J Neurosci 24:3926-3932.

Perrett SP, Ruiz BP, Mauk MD (1993) Cerebellar cortex lesions disrupt learning-dependent timing of conditioned eyelid responses. J Neurosci 13:1708-1718.

Ramachandran R, Lisberger SG (2005) Normal performance and expression of learning in the vestibulo-ocular reflex (VOR) at high frequencies. J Neurophysiol 93:2028-2038.

Rambold H, Churchland A, Selig Y, Jasmin L, Lisberger SG (2002) Partial ablations of the flocculus and ventral paraflocculus in monkeys cause linked deficits in smooth pursuit eye movements and adaptive modification of the VOR. J Neurophysiol 87:912-924.

Raymond JL, Lisberger SG (1996) Behavioral analysis of signals that guide learned changes in the amplitude and dynamics of the vestibulo-ocular reflex. J Neurosci 16:7791-7802.

Raymond JL, Lisberger SG (1998) Neural learning rules for the vestibuloocular reflex. J Neurosci 18:9112-9129.

Reisel D, Bannerman DM, Schmitt WB, Deacon RM, Flint J, Borchardt T, Seeburg PH, Rawlins JN (2002) Spatial memory dissociations in mice lacking GluR1. Nat Neurosci 5:868-873.

Robinson DA (1963) Method of measuring eye movement using a scleral search coil in a magnetic field. IEEE Trans Biomed Electronics 10:137-145.

Saito N, Shirai Y (2002) Protein kinase C $\gamma(\mathrm{PKC} \gamma)$ : function of neuron specific isotype. J Biochem (Tokyo) 132:683-687.

Saito N, Kikkawa U, Nishizuka Y, Tanaka C (1988) Distribution of protein kinase C-like immunoreactive neurons in rat brain. J Neurosci 8:369-382.

Schneiderman N, Gormezano I (1964) Conditioning of the nictitating membrane of the rabbit as a function of CS-US interval. J Comp Physiol Psychol 57:188-195.

Schrenk K, Kapfhammer JP, Metzger F (2002) Altered dendritic development of cerebellar Purkinje cells in slice cultures from protein kinase $\mathrm{C} \gamma$-deficient mice. Neuroscience 110:675-689.

Schweigart G, Mergner T, Evdokimidis I, Morand S, Becker W (1997) Gaze stabilization by optokinetic reflex (OKR) and vestibulo-ocular reflex (VOR) during active head rotation in man. Vision Res 37:1643-1652.

Sears LL, Steinmetz JE (1991) Dorsal accessory inferior olive activity diminishes during acquisition of the rabbit classically conditioned eyelid response. Brain Res 545:114-122.

Shutoh F, Katoh A, Kitazawa H, Aiba A, Itohara S, Nagao S (2002) Loss of adaptability of horizontal optokinetic response eye movements in mGluR1 knockout mice. Neurosci Res 42:141-145.

Shutoh F, Katoh A, Ohki M, Itohara S, Tonegawa S, Nagao S (2003) Role of protein kinase $\mathrm{C}$ family in the cerebellum-dependent adaptive learning of horizontal optokinetic response eye movements in mice. Eur J Neurosci 18:134-142.

Silinsky EM, Searl TJ (2003) Phorbol esters and neurotransmitter release: more than just protein kinase C? Br J Pharmacol 138:1191-1201.

Smith MC, Coleman SR, Gormezano I (1969) Classical conditioning of the rabbit's nictitating membrane response at backward, simultaneous, and forward CS-US intervals. J Comp Physiol Psychol 69:226-231.

Stahl JS, van Alphen AM, De Zeeuw CI (2000) A comparison of video and magnetic search coil recordings of mouse eye movements. J Neurosci Methods 99:101-110. 
Tanaka C, Saito N (1992) Localization of subspecies of protein kinase C in the mammalian central nervous system. Neurochem Int 21: $499-512$

Tatsukawa T, Chimura T, Miyakawa H, Yamaguchi K (2006) Involvement of basal protein kinase $C$ and extracellular signal-regulated kinase $1 / 2$ activities in constitutive internalization of AMPA receptors in cerebellar Purkinje cells. J Neurosci 26:4820-4825.

Van Alphen AM, De Zeeuw CI (2002) Cerebellar LTD facilitates but is not essential for long-term adaptation of the vestibulo-ocular reflex. Eur J Neurosci 16:486-490.

Van Alphen AM, Stahl JS, De Zeeuw CI (2001) The dynamic characteristics of the mouse horizontal vestibulo-ocular and optokinetic response. Brain Res 890:296-305.
Van Beugen BJ, Nagaraja RY, Hansel C (2006) Climbing fiber-evoked endocannabinoid signaling heterosynaptically suppresses presynaptic cerebellar long-term potentiation. J Neurosci 26:8289-8294.

Van Der Zee EA, Luiten PGM, Disterhoft JF (1997) Learning-induced alterations in hippocampal PKC-immunoreactivity: a review and hypothesis of its functional significance. Prog Neurorsychopharmacol Biol Psychiatry 21:531-572.

Villarreal RP, Steinmetz JE (2005) Neuroscience and learning: lessons from studying the involvement of a region of cerebellar cortex in eyeblink classical conditioning. J Exp Anal Behav 84:631-652.

Watanabe E (1984) Neuronal events correlated with long-term adaptation of the horizontal vestibulo-ocular reflex in the primate flocculus. Brain Res 297:169-174. 